\title{
Design for Deconstruction: Futuristic Sustainable Solution for Structural Design
}

\author{
Ali A. Al-Ghalib ${ }^{1 *}$, Dhia B. Ghailan ${ }^{1}$ \\ ${ }^{1}$ Civil Engineering Department, Mustansiriyah University, Baghdad, Iraq
}

\section{Keywords}

Design for deconstruction, Reclaimed (salvaged) steelwork, Embodied energy, Sustainable development, $\mathrm{CO}_{2}$ emission.

\begin{abstract}
The aim of this research is to investigate the sustainability of design for deconstruction on saving: natural raw materials, embodied energy and carbon emission of steel buildings. A methodology is devised to account for designed for upcoming reclaim at the early planning phase. The procedure is relied on PAS2050 method. A steel structure building of two bays of size $(6 \mathrm{~m} \mathrm{x} 8 \mathrm{~m})$ and of $4 \mathrm{~m}$ height is devoted as a case study to assess the methodology. In this case study, three different floor systems are suggested: composite steel deck, hollow core precast concrete planks, and demountable precast composite floor system. The reduced quantity of embodied carbon energy is estimated through considering the steel building. The calculation of embodied carbon of the three models is relied on records of the Inventory of Carbon and Energy (ICE). The results show that $\mathrm{CO}_{2}$ emissions from the building can be dropped around $50 \%$, when design for deconstruction strategy is considered. Design standards and codes lack a little procedure to follow. Therefore, this study also outlines some helpful specifications, guidelines, and detailing of design for deconstruction of steel buildings.
\end{abstract}

\section{Introduction}

\subsection{Motivation}

The climate change and global warming, which are the direct effect of greenhouses gas emissions are becoming great obsession for world's leaders since the sustainable development was first crafted in 1987 by a committee in the United Nations (UN) Brundtland Report entitled 'Our Common Future'. In the UN report, the sustainable development was defined as: 'development that meets the needs and aspirations of the current without undermining the aptitude of forthcoming generations to fulfill their personal needs' [1]. In structural engineering society, as steward of the built environment [2], the focus on sustainability has been focusing on two primary areas: construction materials and structural design techniques. For the construction materials area, the efforts have been devoted to embodied carbon energy, minimizing greenhouse gas emissions, primarily from steel and cement production. Additionally, the effort continues to use recycled materials, mainly steel, and introducing new alternatives for construction materials of lower environmental impact (e.g. carbon fabrics, cardboard components, and recycled fiberreinforced plastics). Manufacturing of Portland cement worldwide is responsible for $6 \%$ of global carbon dioxide $\left(\mathrm{CO}_{2}\right)$ emissions. In the same respective, steel production worldwide is responsible for $7 \%$ of $\mathrm{CO}_{2}$ emissions. Therefore, structural engineers should inevitably be positive in decreasing the impact of the $\mathrm{CO}_{2}$ emission through extending the service life of the materials. Reuse of structural components outperforms recycling, when correct detailing is prepared and obstacles are removed. In this research, reuse literally means using a whole structure or structure components over again. In the same context, the terms reclaimed and salvaged are opposed to the recycled, and are normally used to describe the utilization of elements with minimal processing such as drilling holes for connections, cutting, cleaning and so forth. The general prospective impact of construction materials manufacture on the environment can be minimized more through the recycling and reclamation of material after the deconstruction process of the building. A truly sustainable design system will allow itself to be dismantled and reclaimed to a certain extent than demolition and to integrate materials with recycled content in the newly produced products. In the reclaimed steel procedure, the likely life of steel structural components is gone to extend far-off further than the life of an original building. This practice will minimize the consumption of raw materials as well as it will cut down the $\mathrm{CO}_{2}$ emission.

\subsection{Deconstruction of Steel Structures}

On the structural engineering area, the main effort has been dedicated to explore new structural systems to save material, or design for limited natural resources [3]. In its vision for the future of structural engineering, Structural Engineering Institute (SEI) calls for change to encourage creative thinking to conquer original, environmentally-sensitive, and sustainable design approaches [4]. According to Dowling in 2010, thirteen percent of structural steel sections were being reused in comparison with eighty six percent being recycled [5]. However, the low percent of the reuse can be augmented through the standardization of steel sections, connections and design for deconstruction protocols [6]. For future, structural designers should focus on finding flexible models to let changes in the use of the building or reuse its components. As an example of a building built with recycled materials and greatest flexibility for future adaptation is the Stansted Airport Terminal in England, Figure.1 [7]. In the meantime, the Olympic stadium of London 2012 Olympic Games (Figure.1) is an outstanding example of a structural steelwork that was designed to be dismantled. The upper part of the stadium was designed to be dismantled after the finishing of the Olympic Games [8].

\subsection{Scope}

The paper discusses the present obstacles associated with reuse, and outlines the benefits of steel reuse in framed buildings. Issues such as assessment of reclaimed steel properties, re-certification of steel sections, and potential reuse at early stage of the project design in order to ensure supply are highlighted. There are technical difficulties in nowadays building manifest in composite sections, where welded shear studs connect steel decks to girders; which makes it difficult to 
dismantle the steel girders without damage [9]. This study provides two design techniques for composite floor systems that make a clean salvage process possible. Finally, the main motivation of the study is to show the environmental advantages in considering steel reuse where the embodied energy, carbon emission and other environmental impacts can be preserved or minimized.

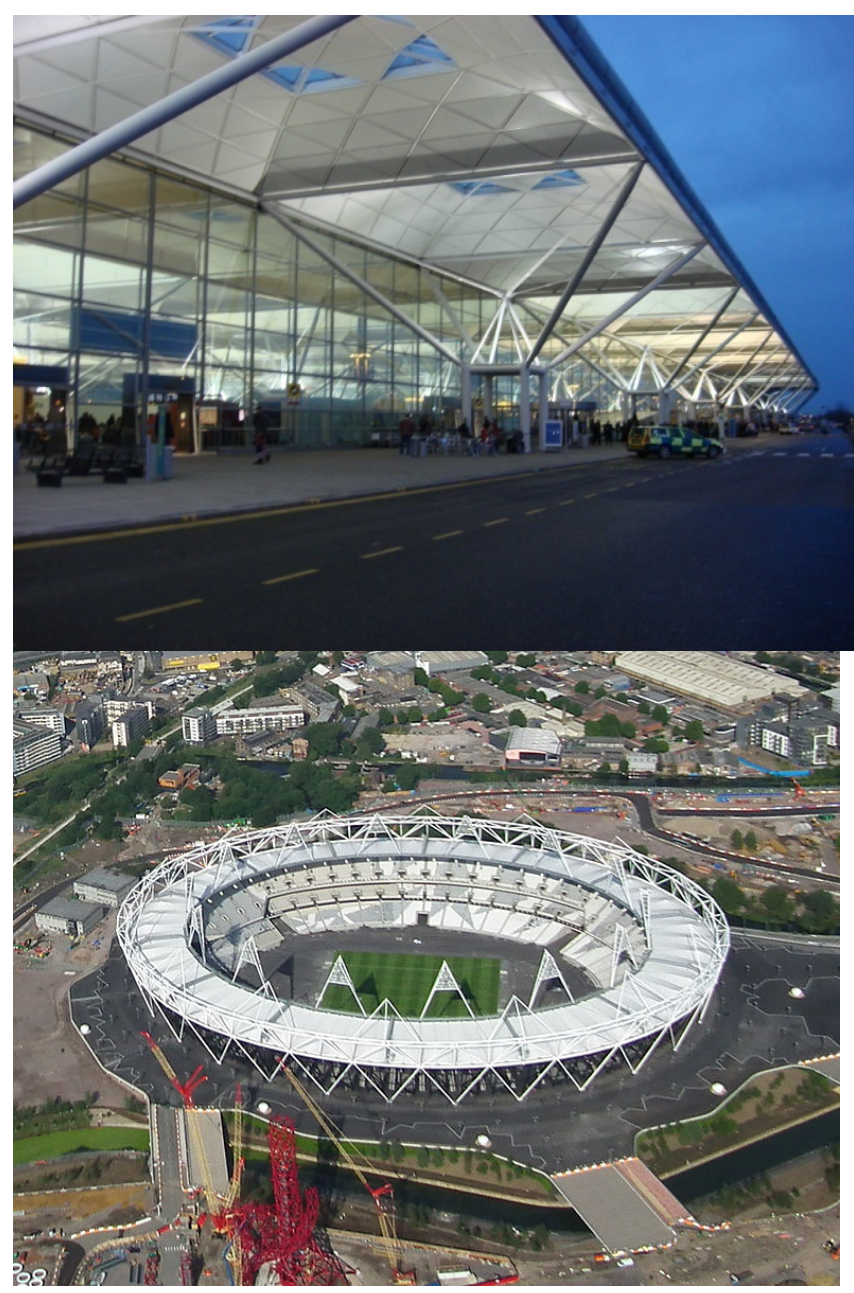

Figure 1. Olympic stadium of London 2012 (top); Stansted Airport Terminal, England (bottom)

\section{Impact of Steel and Cement Production on Environment}

The global tendency of steel and cement production shows the accelerating environmental abuse from current structural design practice and materials. The $\mathrm{CO}_{2}$ emission particularly due to these two construction materials is drawn international concern that structural engineering community should reflect on. Statistical surveys suggest that $64 \%$ of global $\mathrm{CO}_{2}$ emissions comes from energy process (the rest are from deforestation, agriculture or decay); and $24 \%$ of these emissions are industry-related, as shown in Figure 2. Cement and steel productions contribute to the global emissions by $6 \%$ and $7 \%$, respectively, as shown in Figure. 2 [10, 11].

Depletion of natural resources and the need to cut down the environmental effects from production of construction materials are representing a great significance for resource efficiency inside the construction industry. Steel is a proper regenerative design material in that it is recycled several times without losing of material characteristics. In the meantime, it is also a correct salvage construction material, because it can be reused several times before ending in the electric arc furnace for secondary steelmaking recycling. Structural members can frequently being reused instead of recycled as steel exhibits no degradation with use.

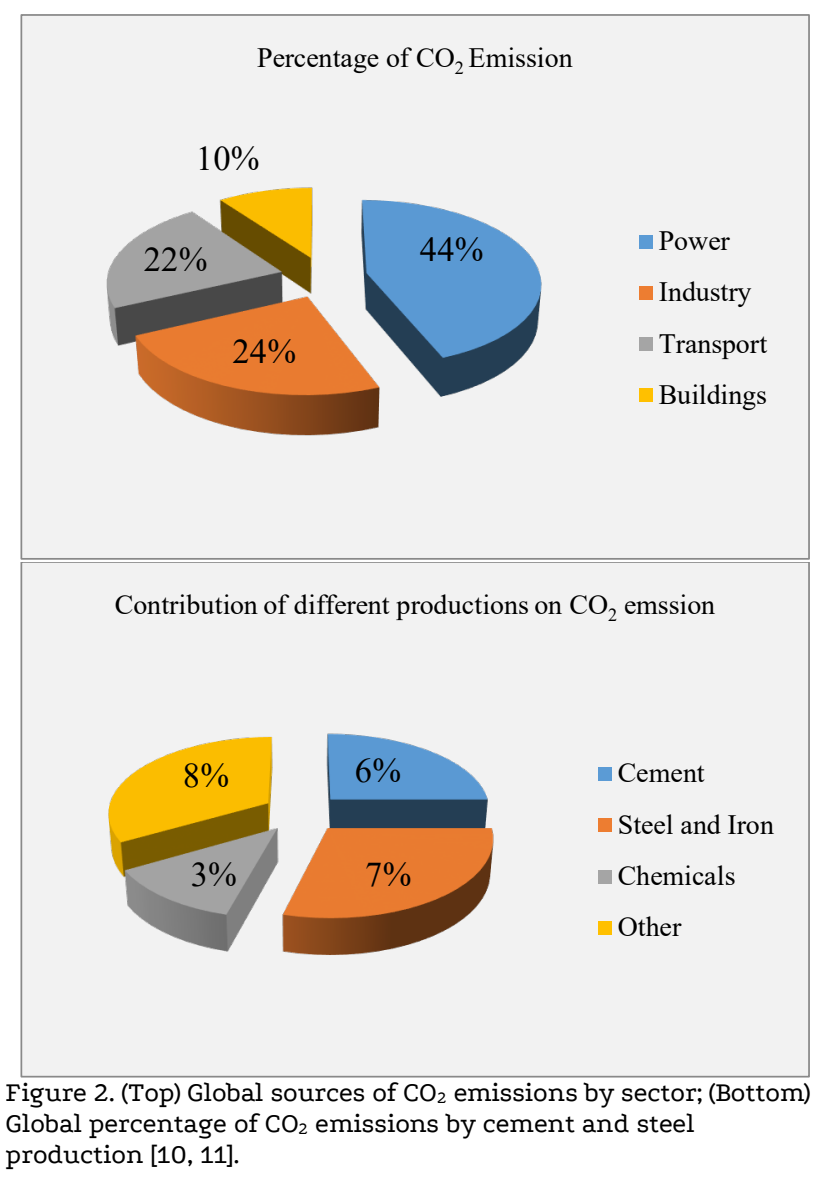

In one direction, the reduction of embodied energy of buildings can be achieved through minimizing the energy required to produce materials. Although recycling process for materials reduces the embodied energy, materials reuse reduces embodied energy quite more.

In order to demonstrate the advantages of design for deconstruction and the reuse of building elements, Figure 3 shows the embodied carbon divided over the numbers of presumed lives, as suggested in the PAS 2050 [12]. This Figure simply shows the advantage of reusing materials in terms of dropping their embodied energy. This case study uses the PAS 2050 approach, which divides up the embodied carbon between the numbers of anticipated lives of the component.

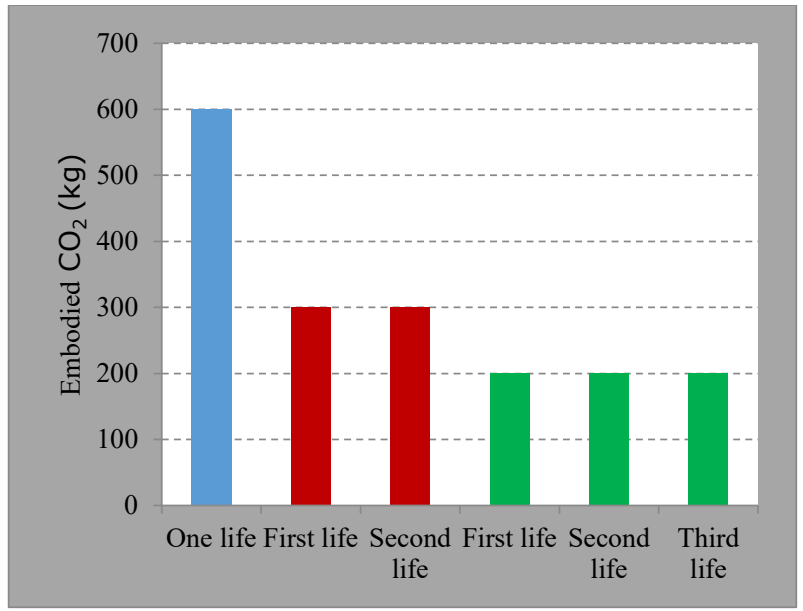

Figure 3. Embodied carbon of $12 \mathrm{~m}$ steel beam W14 x 22 , demonstrating how the impact can be divided over multiple lives 


\section{Design for Deconstruction Protocol}

In order to make the reuse of steel members easy, it is practical that designers optimize their design to facilitate its reuse or adaptation and to avoid some steel construction systems that scarcely dismantled. For instance, designers should favor bolted connections over welded to allow smoothly demountable elements during deconstruction. The connections have to be easily accessible, as well as steel sections are unsupplied with coatings. It is favorable to identify the properties of the members by tagging bar code or keep the original record of the steel products. So far, common steel design institutions (i.e. AISC or EU) have no specific codes of practice for reused steel components. Nonetheless, the requirements of AISC 36010 in Appendix 5, which is devoted to evaluate the existing structures and the Mechanical Testing of ASTM A370 can be followed to run a testing program when the original drawings and specifications of the building are not available [13]. In the last two decades some prominent engineering institutions have established design guidelines to the design for deconstruction practice, for instance SCI, the Steel Construction Institute [14], CIRIA, a British Construction Research Association [15], [16].

\subsection{Specifications Scheme of Design for Deconstruction}

As a valuable effort to generalize a practice of design for deconstruction, Walter Moore's Austin office has developed a system of visual inspection to ensure the integrity of structural steel components [17]. Also, the design office has presented some of the main principles and design detailing for Reclaimed Structural Steel (RSS), which are specifically applied for one of its projects. The following principles represent good starting point for setting a specification for structural steel reuse:

- all RSS shall come from a building structure located in the continental United States and constructed after 1930. The properties of salvaged steel are fairly easy to recognize, in the case that period of construction is identified, as the manufacture of steel was standardized since the beginning of the 20th century [17].

- RSS shall not come from bridge structures, although bridge girders are being used in the construction of new houses [17].

- The designers should use constantly rolled sections for RSS members. No built-up sections are permitted.

- The designers should not utilize riveted, welded, or bolted splices along the span of the RSS members.

- The RSS must be approved for the properties of the section and characteristics of material strength as given on the notes and drawings.

- It is totally not permitted to use RSS members of areas of accelerated spotty corrosion or indicate other signs of local section damage.

- It is not permitted to use elements of existing holes within 3 in of position someplace new holes are to be created.

\subsection{Recommendations for Design for Deconstruction}

It is highly important to mention that reclaimed steel should not be employed in structures subject to earthquakes, fatigue, or in plastic design which depends on formation of plastic hinges. The SCI [14] suggests a protocol based on that reclaimed steel can be used in Consequence class 1, 2 or 3 structures given in Table B1 of BS EN 1990 [18]. Only new steel sections are allowed to be used for curved members, because the reclaimed steel must not processed through a bending machine. Also, reclaimed steel is normally not utilized for steelwork such as banisters and balconies because there is very complicated work obtain the material and manufacturing it to suit its new requirement [17].

For the ultimate limit states, the particular partial factors $\gamma \mathrm{Mi}$ for buildings of both new and reused steelwork can be given in Table 1.
Table 1. Partial factors $\gamma_{\mathrm{Mi}}$ for buildings

\begin{tabular}{llll}
\hline Factor & Definition & $\begin{array}{l}\text { New } \\
{[19]}\end{array}$ & $\begin{array}{l}\text { steelaimed } \\
\text { steel [14] }\end{array}$ \\
\hline$\gamma_{\text {M0 }}$ & $\begin{array}{l}\text { Partial factor for } \\
\text { resistance of cross- } \\
\text { section }\end{array}$ & 1.0 & 1.0 \\
\hline$\gamma_{\text {M1 }}$ & $\begin{array}{l}\text { Partial factor for } \\
\text { resistance of member } \\
\text { stability (buckling) }\end{array}$ & 1.0 & 1.15 \\
& $\begin{array}{l}\text { Partial factor for } \\
\text { resistance of members in } \\
\gamma_{\text {M2 }}\end{array}$ & 1.25 & 1.0 \\
& tension & \\
\hline
\end{tabular}

In this significant change of $\gamma_{\mathrm{M} 1}$, buckling resistance of compression members can be estimated from Equation 1 according to [18].

$$
\frac{N_{E d}}{N_{b, R d}} \leq 1.0
$$

Where: $\mathrm{N}_{\mathrm{Ed}}$ is design value of the compression force; $\mathrm{N}_{\mathrm{b}, \mathrm{Rd}}$ is the buckling resistance of the compression section.

$$
N_{b, R d}=\frac{\lambda A f_{y}}{\gamma_{M 1}}
$$

$\lambda$ is the reduction factor for the specific buckling mode $\gamma_{\mathrm{M} 1}$ is the partial factor for buckling of the member, which is 1.15 in the case of reclaimed steelwork.

\section{Material Properties to be declared for Reclaimed Steelwork}

The steel industry worldwide is highly standardized whereby a structural engineer can accurately be certain about the yield stress of a member if the period in which the section was manufactured is known. Nonetheless, in case the properties of the reclaimed steelwork are obscure, some necessary material properties and how they cab be assessed are shown in Table 2.

Table 2. Assessment of material properties for reclaimed steelwork [14]

\begin{tabular}{lll} 
Item & Property & Process \\
\hline 1 & Yield and ultimate & Destructive or non- \\
2 & strength & destructive tests \\
& Elongation & Destructive tests \\
3 & $\begin{array}{l}\text { Tolerance of } \\
\text { dimensions and shape }\end{array}$ & Measurements survey \\
& A maximum carbon & Manufacturer's test \\
4 & limit of the steel & certificates \\
\hline
\end{tabular}

The non-destructive tests are limited to determining the steel grade. When the steelwork is fabricated and placed in EU market, it must CE Marked to BS EN 1090 product standards whereby properties can be declared. However, reclaimed steelwork must be dealt with in a different way, because it could have been produced to a replaced standard and is most unlikely to have any documented test results from time of manufacture [14].

\section{Embodied $\mathrm{CO}_{2}$ Energy and its Impact on Design for Deconstruction: A case study}

In this case study, the frame structure buildings of two bays of size $(6 \mathrm{~m} \times 8 \mathrm{~m})$ and of $4 \mathrm{~m}$ height are made of steel sections. However, two different floor systems are primarily suggested: composite steel deck and hollow core precast concrete planks, Figure 4. In the first model, the composite deck acts as unit with all the steel beams (primary and secondary). However, the second model's steel beams, columns, and the precast concrete planks are entirely relevant for design for deconstruction and next reuse. The composite steel deck and precast planks along with the carrying steel frames were optimally designed for minimum section size by using ETABS 2016 building design software; the design information data and output of steel sections are shown in Figure 5. AISC 360-10 design code and LRFD design provision were exploited. Steel members were designed for yield stress of $50 \mathrm{ksi}$. 

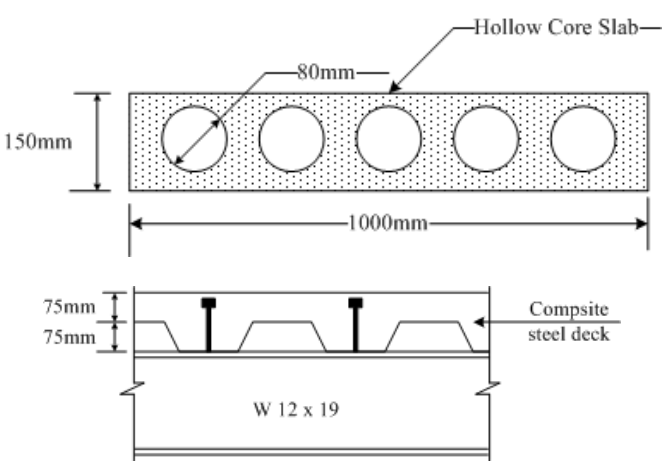

Figure 4. The two different floor systems: composite steel deck and hollow core planks

The life span of the building is assumed to be thirty years. The case study is set in a sixty-year period; in each life span, steel components appropriate for dismantling and reuse. Thus, they have two life cycles, and the environmental impact of reusable structure will be separated in two lives. So as to make future reuse possible by utilizing design for deconstruction system, the embodied carbon impact is efficiently being halved for the steel elements at first use. The additional half of the original environmental impact goes to the second use of those elements. Obviously, whichever component is reproduced for the second new use, the environmental impact of use should be considered. The estimation of embodied carbon of the structural two models is mainly based on database of the Inventory of Carbon and Energy (ICE) [20]. The embodied carbon (EC) computation for the composite deck floor building is given in Table 3, and the EC computation for the precast floor building is given in Table 4.
Table 3. Embodied Carbon (EC) in composite deck floor building

\begin{tabular}{|c|c|c|c|c|c|}
\hline Component & $\begin{array}{c}\mathrm{EC} \mathrm{Kg} \\
\mathrm{CO}_{2} / \mathrm{kg}\end{array}$ & Weight & $\begin{array}{l}\text { Length } \\
\mathrm{m}\end{array}$ & $\begin{array}{c}\text { Total } \\
\mathrm{EC} \\
\mathrm{kg} \\
\mathrm{CO}_{2} \mathrm{e} \\
\end{array}$ & $\begin{array}{c}\text { DfD } \\
\mathrm{EC} \\
\mathrm{kg} \\
\mathrm{CO}_{2} \mathrm{e} \\
\end{array}$ \\
\hline W 14 x 30 (main) & 1.53 & $44.6 \mathrm{~kg} / \mathrm{m}$ & 32 & 2184 & 2184 \\
\hline W 16 x 26 (main) & 1.53 & $38.7 \mathrm{~kg} / \mathrm{m}$ & 12 & 711 & 711 \\
\hline $\begin{array}{l}\text { W } 12 \text { x } 19 \\
\text { (secondary) }\end{array}$ & 1.53 & $28.3 \mathrm{~kg} / \mathrm{m}$ & 36 & 1559 & 1559 \\
\hline W 12 x 96 (column) & 1.53 & $\begin{array}{l}142.8 \\
\mathrm{~kg} / \mathrm{m}\end{array}$ & 24 & 5244 & 2622 \\
\hline $\begin{array}{l}\text { Concrete } 2300 \\
\mathrm{~kg} / \mathrm{m}^{3}\end{array}$ & 0.132 & $33120 \mathrm{~kg}$ & - & 4372 & 4372 \\
\hline Steel mesh $(6 \times 6)$ & 1.40 & $0.92 \mathrm{~kg} / \mathrm{m} 2$ & - & 124 & 124 \\
\hline $\begin{array}{l}\text { Shear studs } \\
(19 \mathrm{~mm} \times 100 \mathrm{~mm})\end{array}$ & 1.66 & $0.22 \mathrm{~kg}$ & $\begin{array}{l}160 \\
\text { studs }\end{array}$ & 35 & 35 \\
\hline \multirow[t]{3}{*}{ Profile Steel deck } & 1.54 & $0.6 \mathrm{~kg} / \mathrm{m} 2$ & - & 89 & 89 \\
\hline & & & Total & 14318 & 11696 \\
\hline & & & Total $/ \mathrm{m}^{2}$ & 150 & 122 \\
\hline
\end{tabular}

Table 4. Embodied Carbon (EC) in precast floor building

\begin{tabular}{|c|c|c|c|c|c|}
\hline Component & $\begin{array}{c}\mathrm{EC} \mathrm{Kg} \\
\mathrm{CO}_{2} / \\
\mathrm{kg}\end{array}$ & Weight & $\begin{array}{l}\text { Length } \\
\mathrm{m}\end{array}$ & $\begin{array}{c}\text { Total } \\
\text { EC kg } \\
\mathrm{CO}_{2} \mathrm{e}\end{array}$ & $\begin{array}{c}\text { DfD EC } \\
\mathrm{kg} \\
\mathrm{CO}_{2} \mathrm{e}\end{array}$ \\
\hline $\begin{array}{l}\text { W } 14 \times 22 \\
\text { (main) }\end{array}$ & 1.53 & $\begin{array}{c}32.7 \\
\mathrm{~kg} / \mathrm{m}\end{array}$ & 40 & 2001 & 1000.5 \\
\hline $\begin{array}{l}\text { W } 16 \times 26 \\
\text { (main) }\end{array}$ & 1.53 & $\begin{array}{r}38.7 \\
\mathrm{~kg} / \mathrm{m}\end{array}$ & 6 & 355 & 177.5 \\
\hline $\begin{array}{l}\text { W } 12 \times 96 \\
\text { (column) }\end{array}$ & 1.53 & $\begin{array}{l}142.8 \\
\mathrm{~kg} / \mathrm{m}\end{array}$ & 24 & 5244 & 2622 \\
\hline $\begin{array}{l}\text { Concrete } \\
2300 \mathrm{~kg} / \mathrm{m}^{3}\end{array}$ & 0.132 & $27600 \mathrm{~kg}$ & - & 3643 & 1821.6 \\
\hline \multirow[t]{3}{*}{ Rebar } & 1.40 & $1200 \mathrm{~kg}$ & - & 1680 & 840 \\
\hline & & & Total & 12923 & 6461.5 \\
\hline & & & Total $/ \mathrm{m}^{2}$ & 134.6 & 67.3 \\
\hline
\end{tabular}

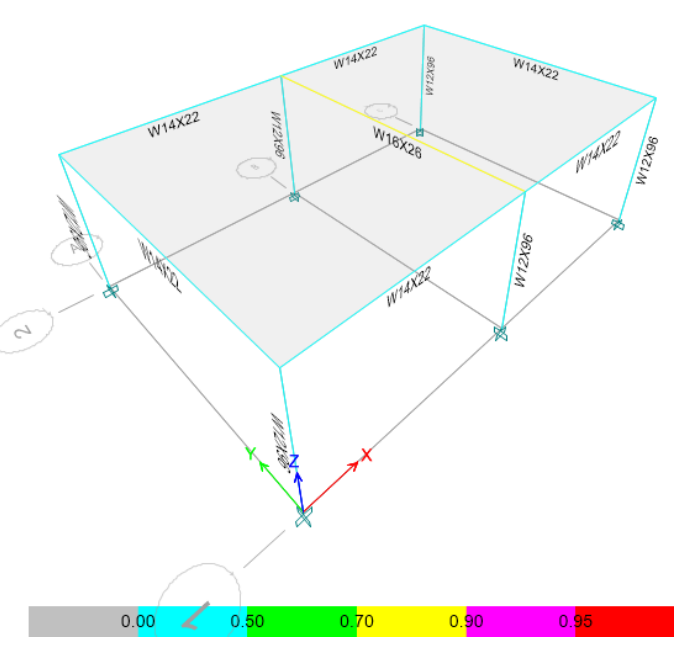

Figure 5. The outputs of two structural steel models (composite and precast)

In composite deck flooring system, the concrete floor is fixed on the secondary and main members by shear studs. The secondary and main members are not being designed for reuse because considerable damage occurs in the beam when the shear studs are needed to be removed. Nevertheless, the columns can be easily demountable from the structure with a small damage when double cleat angle connections with bolting will be used. When the hollow core precast planks flooring with steel components are used, the advantages of utilizing design for deconstruction system is clearly made the embodied carbon reduced by just about $50 \%$.

Framed steel structures are superior preferences for design for deconstruction projects, because the components are easily to be designed for deconstruction. On contrary, cast-in-site concrete framed buildings are not demountable, however steelwork frame buildings using prefabricated modular concrete units or prefabricated concrete systems are readily demountable considering special 
detailing and section type. An example of inspiring model for a dismantled composite concrete slab system was developed by the Walter P. Moore, which is given in Figure 6 [17]is adopted in this research to show the amount of embodied energy for such framed steel and concrete structures. Additionally, Moynihan and Allwood in 2014 suggested successfully a demountable connection that permits composite reuse of both components at the end of building life. In their design, the behavior of steel bolts as demountable composite connectors were investigated same as manually welded studs [21].

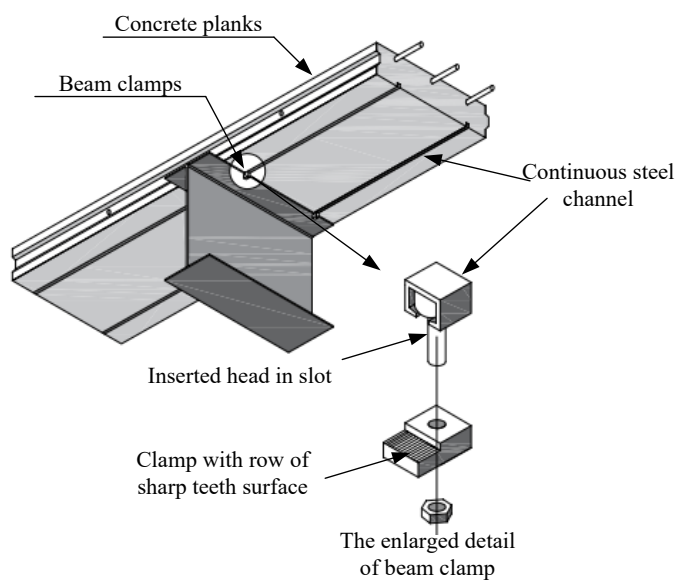

Figure 6. Dismantled composite flooring system developed by Walter P. Moore adapted after [21]

The composite flooring detail (shown in Figure 6) is assumed to be used instead of the composite deck flooring system of Figure 4, the embodied carbon manageably reduced by about $50 \%$ as well. Table 5 shows the calculation of the EC when the building shown in Figure 5 of dismantled composite flooring is considered.

It is the procedure of design that ensures the advantage from design for deconstruction. When the design for deconstruction scheme is considered, the non-composite system produces the smallest possible amount of carbon. This is because of the maximum salvaged steel members being designed for reuse. While, the composite floor system design entails that all of the beams are compositely built and as a result cannot be reused. Nevertheless, efforts are being made to devise demountable composite system with flexible reuse. For more examples on the wide research interest in the area of demountable composite slab floor systems, recent investigations were performed by Lawan et al. [22] also by Gritsenko et al. [23], Ataeia et al [24], Patel et al [25].

Table 5. Embodied Carbon (EC) in building of dismantled composite flooring

\begin{tabular}{|c|c|c|c|c|c|}
\hline Component & $\begin{array}{c}\mathrm{EC} \mathrm{Kg} \\
\mathrm{CO}_{2} / \\
\mathrm{kg}\end{array}$ & Weight & $\begin{array}{c}\text { Length } \\
\mathrm{m}\end{array}$ & $\begin{array}{c}\text { Total } \\
\mathrm{EC} \\
\mathrm{kg} \\
\mathrm{CO}_{2} \mathrm{e}\end{array}$ & $\begin{array}{c}\text { DfD } \\
\mathrm{EC} \\
\mathrm{kg} \\
\mathrm{CO}_{2} \mathrm{e}\end{array}$ \\
\hline $\begin{array}{l}\mathrm{W} 14 \times 30 \\
\text { (main) }\end{array}$ & 1.53 & $44.6 \mathrm{~kg} / \mathrm{m}$ & 32 & 2184 & 1092 \\
\hline $\begin{array}{l}\text { W } 16 \times 26 \\
\text { (main) }\end{array}$ & 1.53 & $38.7 \mathrm{~kg} / \mathrm{m}$ & 12 & 711 & 356 \\
\hline $\begin{array}{l}\text { W } 12 \text { x } 19 \\
\text { (secondary) }\end{array}$ & 1.53 & $28.3 \mathrm{~kg} / \mathrm{m}$ & 36 & 1559 & 780 \\
\hline $\begin{array}{l}\text { W } 12 \times 96 \\
\text { (column) }\end{array}$ & 1.53 & $\begin{array}{l}142.8 \\
\mathrm{~kg} / \mathrm{m}\end{array}$ & 24 & 5244 & 2622 \\
\hline $\begin{array}{l}\text { Dismantled } \\
\text { concrete } \\
2300 \mathrm{~kg} / \mathrm{m}^{3}\end{array}$ & 0.132 & $33120 \mathrm{~kg}$ & & 4372 & 2186 \\
\hline \multirow[t]{3}{*}{$\begin{array}{l}\text { Steel mesh } \\
(6 \times 6)\end{array}$} & 1.40 & $0.92 \mathrm{~kg} / \mathrm{m}^{2}$ & & 124 & 62 \\
\hline & & & Total & 14194 & 7098 \\
\hline & & & Total $/ \mathrm{m}^{2}$ & 148 & 74 \\
\hline
\end{tabular}

Table 6. Embodied Carbon (EC) in building of dismantled composite flooring

\begin{tabular}{lccc}
\hline & $\begin{array}{c}\text { Composite } \\
\text { deck floor } \\
\text { building }\end{array}$ & $\begin{array}{c}\text { Precast } \\
\text { floor } \\
\text { building }\end{array}$ & $\begin{array}{c}\text { Dismantled } \\
\text { composite } \\
\text { flooring } \\
\text { building }\end{array}$ \\
\cline { 2 - 4 } & EC kg CO $2 \mathrm{e}$ & $\begin{array}{c}\mathrm{EC} \mathrm{kg} \\
\mathrm{CO}_{2} \mathrm{e}\end{array}$ & EC kg CO $2 \mathrm{e}$ \\
$\begin{array}{l}\text { Design for } \\
\text { demolition } \\
\text { protocol } \\
\begin{array}{l}\text { Design for } \\
\text { deconstruction } \\
\text { protocol }\end{array}\end{array}$ & 14318 & 12923 & 14194 \\
\hline
\end{tabular}

\section{Discussion}

In the course of this study, a range of two-bay steel building types of different flooring system is investigated. The building structure is manufactured of steel because the steel is practical when designing steel frames for projected deconstruction. The steel frames are elastically designed for the least safe section using ETABS 2016 building design software. The results given in the study is presented for a two-bay building to find out significance of saving in embodied energy, which can easily be reflected on savings on a whole structure.

A comparison of the embodied carbon energy of the three building types is shown alongside in Table 6. For the normal design (design for demolition protocol) the three structural models have very close embodied carbon energy. Nevertheless, after design for deconstruction is presented the building of precast flooring system entails the least embodied carbon because the highest number of steel sections assigned for reuse. While for the building of composite deck floor the main and secondary beams attached to the profile steel deck are unable to be reclaimed. The results of embodied carbon presented in this case study are real and depend on record of the ICE, therefore the main outcomes can reasonably be translated to all comparable structures.

\section{Conclusions}

This study validates the feasibility of adopting design for deconstruction of steel buildings as a strategy to save embodied carbon energy. It appraises a tool to allocate the advantages of design for deconstruction. In the pilot studies, the comparison of the embodied carbon energy of a typical steel frame building considering hollow core precast concrete floor system instead of composite steel deck floor system shows that $\mathrm{CO}_{2}$ emissions can be dropped in so far as $50 \%$. Although composite deck floor has the highest embodied carbon for the standard design or design for deconstruction, it is possible to follow a special detail for dismantled composite floor to compensate the amount of embodied energy. There is growing attention being concentrated towards minimizing carbon emissions and enhancing the possibly of material reuse in the construction industry. However, traditional composite systems are identified as challenging in different aspects. The plan to minimize the embodied energy as much as possible entails encouraging designers to switch to design for deconstruction protocol. By using simple connections with standard details, and through minimizing the number of different steel sections, the salvaged materials can be reclaimed over again.

Although composite systems are advised to be avoided in buildings readily designed to adapt and deconstruct, a creative detail of composite system with potential reuse is brought to that can be dismantled. The limited stock of the salvage steel elements nowadays necessitates surveying the salvageable steel before starting the design of the new structure. The dimensions of the salvaged steel members impose the floor-to-floor heights and the bay sizes with a least amount of manufacture. 


\section{Declaration of Conflict of Interests}

The authors declare that publication of this research causes no potential conflict of interest.

\section{References}

[1.] United Nation (UN). Our Common Future. The World Commission on Environment and Development. NY, USA : United Nation, (1987).

[2.] Cocke, D. Updating the vision for the future of structural engineering. Structure Magazine. (2018)

[3.] Bank, L. C. Is structural engineering education sustainable? Structure Magazine. (2015).

[4.] SEI. A vision for the future of structural engineering and structural engineers: a case for change. Virginia, USA : Structural Engineering Institute (SEI), 2013.

[5.] NSC. Newsteelconstruction. [Online] British Construction Steelwork Association and Steel for Life, (2019). [Cited: 1512020. https://www.newsteelconstruction.com/wp/steel-the-neverending-story.

[6.] Sustainable Steel Construction. Burgan, B. A and Sansom, M. R. 62, Journal of Construction Steel Research, Vol. 11, pp. 1178-1183, (2006).

[7.] Sustainable Engineering: The Future of Structural Design. Ochsendorf, J. A. Virginia, USA : ASCE, Structures Congress 2005 Metropolis and Beyond, (2005).

[8.] Tingley, D. D. Design for Deconstruction: An Appraisal, PhD Thesis. Sheffield, UK : The University of Sheffield, (2012).

[9.] Reuse of Structural Steel: the opportunities and challenges. Tingley, D. D and Allwood, J. M. Teeside, UK : s.n., European Steel Environment\& Energy Congress, (2014).

[10.] IEA. Energy and Climate Change, Special Report. Paris, France: International Energy Agency, (2015).

[11.] Purvis, A. Steel and $\mathrm{CO} 2$ - a global perspective. IEA workshop. [Online] $20 \quad$ November 2017 https://iea.blob.core.windows.net/assets/imports/events/245/IST RM_Session1_A._PURVIS_241117.pdf.

[12.] PAS 2050. Guide to PAS 2050- How to assess the carbon footprint of goods and services. s.l.: BSI, Carbon Trust \& DEFRA Document, (2008).

[13.] Reclaimed Structural Steel and LEED Credit MR 3- Materials Reuse. Winters- Downey, E., Modern Steel Construction Journal, (2010).

[14.] Brown, D. G., Pimentel, R. J. and Sansom, M. R. Structural steel reuse: assessment, testing and design principles. Berkshire, UK : The Steel Construction Institute (SCI), (2019).

[15.] Addis, W and Schouten, J. Design for Deconstruction: Principles of design to facilitate reuse and recycling: C607. London, UK : Construction Industry \& Information Association (CIRIA), (2004).

[16.] CSA, Canadian Standards Association. Guidelines for design for disassembly and adaptability in buildings. Ontario, Canada: CSA Z782-06, (2006).

[17.] SEI ASCE. Sustainability guidlines for the structural engineer. [ed.] Dirk M. Kestner, Jennifer Goupil and Lorenz Emily. Virginia, USA : American Society of Civil Engineers (ASCE), (2010).

[18.] BS EN 1993-1-1. Eurocode 3: Design of steel structures- part 1-1: general rules and rules for buildings. Brussels, Belgium: Management center, (2005).
[19.] BS EN 1990:2002. Eurocode- Basis of structural design. Brussels, Belgium: Management center, (2002).

[20.] Hammond, G and Jones, C. Inventory of Carbon \& Energy (ICE), Version 2.0. Bath, UK: Sustainable Energy Research Team (SERT), Department of Mechanical Engineering, University of Bath, (2011).

[21.] Viability and performance of demountable composite connectors. Moynihan, M. C and Allwood, J. M., Journal of Constructional Steel Research, pp. 47-56, (2014).

[22.] Lawan, M, Tahir, M and Mirza, J. 2016. Bolted Shear Connectors Performance in Self-Compacting Concrete Integrated with ColdFormed Steel Section. Latin American Journal of Solids and Structures., (2016), pp. 731-749. doi.org/10.1590/1679-78252004

[23.] Gritsenko, A, Nijgh, M P and Veljkovic, M.Towards a Demountable Composite Slab Floor System. Copenhagen: Ernst \& Sohn Verlag für Architektur und technische Wissenschaften GmbH \& Co. KG, Berlin, the 14th Nordic Steel Construction Conference, (2019). doi.org/10.1002/cepa.1052.

[24.] Ataeia A, Bradford M, Valipour H, Sustainable Design of Deconstructable Steel-Concrete Composite Structures, Procedia Engineering, Volume 145, pp. 1153-1160, (2016). doi.org/10.1016/j.proeng.2016.04.149

[25.] Patel V, Uy B., Pathirana S., Wood S., Singh M., Trang B, Finite Element Analysis of Demountable Steel-Concrete Composite BeamsUnder Static Loading, Advanced Steel Construction, Volume 14, Issue 3, (2018), pp. 392-411. DOI:10.18057/IJASC.2018.14.3.5

\section{How to Cite This Article}

Al-Ghalib, A., Ghailan, D., Design for Deconstruction: Futuristic Sustainable Solution for Structural Design, Civil Engineering Beyond Limits, 1 (2021), 6-11. https://doi.org/10.36937/cebel.2021.001.002 